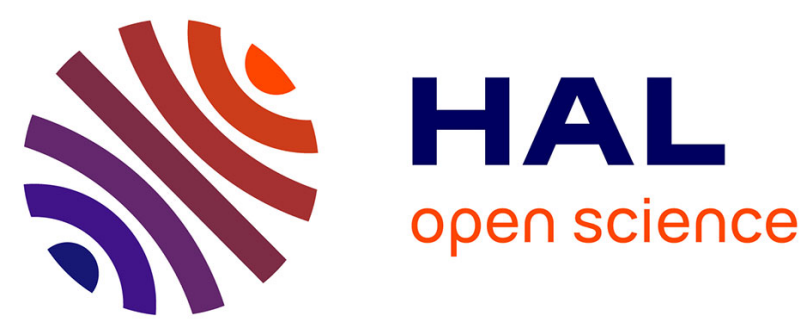

\title{
Variations in ozone depletion potentials of very short-lived substances with season and emission region
} Jérôme Brioude, Robert W. Portmann, John S. Daniel, Owen R. Cooper, Gregory J. Frost, Karen H. Rosenlof, Claire Granier, A. R. Ravishankara, Stephen A. Montzka, Andreas Stohl

\section{To cite this version:}

Jérôme Brioude, Robert W. Portmann, John S. Daniel, Owen R. Cooper, Gregory J. Frost, et al.. Variations in ozone depletion potentials of very short-lived substances with season and emission region. Geophysical Research Letters, 2010, 37 (19), pp.L19804. 10.1029/2010GL044856 . hal-00512780

\author{
HAL Id: hal-00512780 \\ https://hal.science/hal-00512780
}

Submitted on 22 Feb 2016

HAL is a multi-disciplinary open access archive for the deposit and dissemination of scientific research documents, whether they are published or not. The documents may come from teaching and research institutions in France or abroad, or from public or private research centers.
L'archive ouverte pluridisciplinaire HAL, est destinée au dépôt et à la diffusion de documents scientifiques de niveau recherche, publiés ou non, émanant des établissements d'enseignement et de recherche français ou étrangers, des laboratoires publics ou privés. 


\title{
Variations in ozone depletion potentials of very short-lived substances with season and emission region
}

\author{
J. Brioude, ${ }^{1,2}$ R. W. Portmann, ${ }^{1}$ J. S. Daniel,,${ }^{1}$ O. R. Cooper, ${ }^{1,2}$ G. J. Frost,,${ }^{1,2}$ \\ K. H. Rosenlof, ${ }^{1}$ C. Granier, ${ }^{1,2,3}$ A. R. Ravishankara, ${ }^{1}$ S. A. Montzka, ${ }^{4}$ and A. $\mathrm{Stohl}^{5}$ \\ Received 27 July 2010; revised 20 August 2010; accepted 27 August 2010; published 2 October 2010.
}

[1] We present a new approach for calculating the fraction of very-short lived substances (VSLS) emitted at the surface (and their degradation products) that reach the stratosphere $(\beta)$ using the FLEXPART Lagrangian model. The values of $\beta$ play a key role in determining the efficiency of these compounds for depleting stratospheric ozone, and are used to estimate ozone depletion potentials (ODPs) of several short-lived compounds. Calculated $\beta$ and ODPs of VSLSs show large regional and seasonal variability owing to the importance of convective transport. For instance, $\beta$ and ODPs associated with emissions from the Indian subcontinent is an order of magnitude larger than that from Europe, mid-latitude North America, or East Asia. The seasonal cycle of $\beta$ is mainly driven by transport efficiency from the boundary layer into the tropical stratosphere; $\beta$ has a minimum in winter and a maximum in summer. Citation: Brioude, J., R. W. Portmann, J. S. Daniel, O. R. Cooper, G. J. Frost, K. H. Rosenlof, C. Granier, A. R. Ravishankara, S. A. Montzka, and A. Stohl (2010), Variations in ozone depletion potentials of very short-lived substances with season and emission region, Geophys. Res. Lett., 37, L19804, doi:10.1029/2010GL044856.

\section{Introduction}

[2] The Montreal Protocol with its subsequent amendments and adjustments have led, and will likely continue to lead, to the replacement of chlorofluorocarbons (CFCs), Halons (brominated chemicals) and hydrochlorofluorocarbons (HCFCs) with chemicals that are shorter lived or do not contain either chlorine or bromine. Over the past two decades, potential substitutes with lifetimes as short as a few days have been considered.

[3] The concept of the ozone depletion potential (ODP) was developed for CFCs and other long-lived chlorinecontaining molecules to provide a simple measure of the relative ozone-destroying capabilities of these compounds. Due to their long lifetimes, these molecules are well-mixed in the troposphere. This is not true for very short-lived substances (VSLS) whose chemical lifetime is short (less than 6 months) in the troposphere and whose degradation

\footnotetext{
${ }^{1}$ Chemical Sciences Division, Earth System Research Laboratory, NOAA, Boulder, Colorado, USA.

${ }^{2}$ Also at CIRES, University of Colorado at Boulder, Boulder, Colorado, USA.

${ }^{3}$ Also at LATMOS, IPSL, INSU, CNRS, UPMC Universite Paris 6, Paris, France.

${ }^{4}$ Global Monitoring Division, Earth System Research Laboratory, NOAA, Boulder, Colorado, USA.

${ }^{5}$ Norwegian Institute for Air Research, Kjeller, Norway.

Copyright 2010 by the American Geophysical Union. 0094-8276/10/2010GL044856
}

product gases can also be quickly removed via heterogeneous processes [Ko et al., 2003; Law et al., 2007]. VSLS are transported to the stratosphere much less efficiently than the long-lived CFCs. Their successful transport to the stratosphere can depend strongly on the presence of deep convection near their source region.

[4] Irreversible troposphere to stratosphere transport (TST) of chemicals deep into the stratosphere occurs predominantly through the tropical tropopause layer (TTL). The amount of halogen from VSLS reaching the TTL is determined by their emissions as well as convective transport, advection, mixing and removal (via chemical and other loss mechanisms, e.g., rainout) [Fueglistaler et al., 2009; Gettelman et al., 2009]. Using a 1-D model, Gettelman et al. [2009] have shown that convective transport controls the distribution of species with a lifetime of $\sim 1$ month, or less, in the TTL up to the tropopause. Additionally, it has been found that boundary layer source regions for rapid TST are geographically localized [Berthet et al., 2007; Aschmann et al., 2009] to regions of frequent convection. In the tropics, rapid TST occurs from the western Pacific Ocean, the Indian subcontinent and Indonesia region.

[5] Depending on the season and location of emission, VSLS can have highly variable tropospheric removal rates due to differences in their rates of degradation by $\mathrm{OH}$ and photolysis; thus they have variable local lifetimes. These short and variable lifetimes, coupled with inhomogeneous emission patterns, cause VSLS to be unevenly mixed in the troposphere. The inhomogeneity in abundances and the variations in efficiency of TST make the ODPs of VSLS dependent on the location and season of emission. Because of this complexity, no simple method currently exists to accurately calculate the ODP of halogenated VSLS and their dependence on location and season of emission. Wuebbles et al. [2001] and Li et al. [2006] examined spatial dependencies of the ODPs of VSLS using 2-D and 3-D models. They showed that ODPs of $n-\mathrm{C}_{3} \mathrm{H}_{7} \mathrm{Br}$ and $\mathrm{CF}_{3} \mathrm{I}$ depend on the latitude of the source region, with the largest values associated with tropical emissions. Clearly, meteorological variability and conditions dictate the transport and ODPs of these VSLS. However, seasonal and regional variations in ODPs based on actual meteorological data have not been reported.

[6] In this study, we calculate the mass fraction $(\beta)$ of VSLSs emitted at the surface that is transported to the stratosphere either as the original source gas or as halogenated products of the source gas degradation. The transport calculations use meteorological reanalysis for 2003-2006 period and include tropospheric photochemical loss processes. We also present an approach to estimate ODP values from the $\beta$ calculations. We quantify the magnitude of the $\beta$ 
and ODP for a representative set of VSLS emitted from Europe, mid-latitude North America, East Asia and the Indian subcontinent. These four regions were chosen for the following reasons: 1) they are currently, or soon expected to be, strong contributors of anthropogenic VSLS; 2) they represent diverse transport regimes; and 3) the local lifetimes of VSLS are expected to differ due to variations in actinic flux and temperature. We generalized our $\beta$ results so they can be used to estimate the ODPs of other VSLS without the need for an atmospheric model.

\section{Method}

[7] We use the formula given by Ko et al. [2003] that is appropriate for calculating the semi-empirical ODP of a VSLS, $x$, as a function of emission location (s) and time (t), denoted ODP $(\mathrm{s}, \mathrm{t})$ :

$$
O D P_{x}(s, t)=\frac{M_{C F C-11}}{M_{x}} \frac{n_{x}}{n_{C F C-11}} \frac{\zeta_{x} \tau_{\text {strat }}^{x}}{\zeta_{C F C-11} \tau_{\text {strat }}^{C F C-11}} \alpha_{x} \beta_{x}(s, t)
$$

The formula represents the ratio between the loss of stratospheric ozone due to the emission of a unit mass of VSLS $x$ to that by the emission of a unit mass of CFC-11. MCFC-11 and Mx represent the molecular weights of CFC-11 and VSLS $x$, respectively. $\mathrm{nx}$ and $\mathrm{n}_{\mathrm{CFC}-11}$ are the number of halogen atoms per molecule of $x$ and CFC-11. $\zeta_{\mathrm{x}} / \zeta_{\mathrm{CFC}-11}$ accounts for the difference in ozone depletion due to the difference in stratospheric distribution of inorganic halogen from CFC-11 and $x . \tau_{\text {strat }}^{x}$ and $\tau_{\text {strat }}^{C F-11}$ denote the stratospheric residence times of inorganic halogens from $x$ and CFC-11. $\tau_{\text {strat }}^{x}$ is about 2 years [Rosenlof, 1995]. $\tau_{\text {strat }}^{C F C-11}$ is larger than $\tau_{\text {strat }}^{x}$ because CFC-11 dissociates at a higher altitude. The species considered here have tropospheric lifetimes less than, or on the order of, one month. We assume that $x$ is totally dissociated as it enters the stratosphere (or shortly thereafter) and that the terms $\zeta_{\mathrm{x}} / \zeta_{\mathrm{CFC}-11}$ and $\tau_{\text {strat }}^{x} / \tau_{\text {strat }}^{C F-11}$ are independent of $x$ (being integrated over the whole stratosphere and time). $\frac{\zeta_{x} \tau_{\text {strat }}^{x}}{\zeta_{C F C-11} \tau_{\text {strat }}^{C F-11}}$ has not been previously evaluated and is assumed here to be constant for all VSLS and equal to 1 . This assumption is important to the absolute value of the calculated ODPs, but we do not expect uncertainties associated with this value to alter the conclusions regarding the relative ODP variability with season or emission location. This term is expected to be approximately the same for all VSLSs and emission regions because TST transport to heights above $380 \mathrm{~K}$ (the approximate tropical tropopause level) occurs preferentially in the tropics and subtropics and because the VSLS considered here are completely dissociated soon after entering the stratosphere. $\alpha_{\mathrm{x}}$ denotes the ozone depletion efficiency of the halogen in $x$ compared to chlorine; it is about 60 for bromine [Law et al., 2007] and 150 to 300 for iodine [Ko et al., 2003]. More details regarding the derivation and applicability of this formula can be found in the auxiliary material. ${ }^{1} \beta_{\mathrm{x}}(\mathrm{s}, \mathrm{t})$, a primary focus of this work, represents the mass fraction of compound $x$ emitted at the surface that reaches the stratosphere in the form of the source gas $x$ or in the form of halogenated products of $x$. In this study, $\beta_{\mathrm{x}}(\mathrm{s}, \mathrm{t})$

\footnotetext{
${ }^{1}$ Auxiliary materials are available in the HTML. doi:10.1029 2010GL04856.
}

includes the flux of halogens to the stratosphere from the source gas and from its dissociated products. These calculations include the regionally-dependent transport efficiency from the surface into the TTL, degradation of $x$ by $\mathrm{OH}$ and photolysis, the loss of product gases in the troposphere by wet removal of the dissociated products, and the transport through the TTL into the base of the tropical pipe in the stratosphere (see below). The key new feature of this study is the direct calculation of $\beta_{\mathrm{x}}$ using a Lagrangian model that is driven by meteorological reanalysis fields.

[8] To simulate VSLS transport to the top of the TTL (at approximately $430 \mathrm{~K})$ and calculate $\beta_{\mathrm{x}}(\mathrm{s}, \mathrm{t})$, we used the FLEXPART Lagrangian particle dispersion model [Stohl et al., 2005, and references therein] driven by ECMWF ERA-interim meteorological data from 2003 to 2006 (ECMWF ERA-Interim Project. The used dataset, ds627.0, is published by the CISL Data Support Section at the National Center for Atmospheric Research, Boulder, CO and available online at http://dss.ucar.edu/datasets/ds627.0/). FLEXPART has been used to successfully simulate stratosphere-troposphere exchange (STE) [e.g., James et al., 2003]. It includes a convective parameterization scheme, which accounts for the unresolved convectively driven vertical transport [Emanuel and Živković-Rothman, 1999]. Anthropogenic VSLS emissions from the 4 regions in the model are assigned using the anthropogenic CO emission pattern from the EDGAR version 3.2 emission inventory (Figure S1 in the auxiliary material). For ease of calculation, $\mathrm{CO}$ emission patterns are assumed to represent those of anthropogenic VSLS. CO is likely a good proxy for those VSLS emitted from applications such as refrigeration, air conditioning (mobile and stationary), foam blowing, and fire extinguishment that are concentrated in urban areas. However, $\mathrm{CO}$ is unlikely to be the best proxy for emissions from agricultural uses (e.g., $\left.\mathrm{CH}_{3} \mathrm{I}\right)$ and is a poor proxy for natural ocean emissions (e.g., $\mathrm{CH}_{3} \mathrm{I}, \mathrm{CHBr}_{3}$, and $\mathrm{CH}_{2} \mathrm{ClI}$ ) or releases of VSLS from aircraft. The difference in transport efficiency from the surface into the TTL due to differences in emission pattern within each region requires further investigation.

[9] To calculate $\beta$, transport of each VSLS is simulated from the surface source location for 4 months. In the troposphere, the VSLSs considered here are totally removed by degradation and wet removal within this period. We assumed that airmasses reaching $430 \mathrm{~K}$ become entrained in the large-scale ascent of the Brewer-Dobson circulation [Fueglistaler et al., 2009]. Thus, any halogen that is transported above this level is assumed to reside in the stratosphere, with the subsequent stratospheric halogen loss determined by the average transport time from the stratosphere to the troposphere ( 2 years [Rosenlof, 1995]). For the halogen that does not reach $430 \mathrm{~K} 4$ months after emission, we applied a weighting factor that varies with altitude to account for the subsequent transport from the TTL to $430 \mathrm{~K}$. This factor varies from 0.25 at $380 \mathrm{~K}$ to 1 at $430 \mathrm{~K}$. Calculations are performed daily emissions between September 2003 and July 2006, and are given as monthly averages. The $\beta$ value calculated at the end of the 4-month simulation is assigned to the month of emission.

[10] While parcels are in the troposphere, we calculate losses due to photolysis and chemical reactions with $\mathrm{OH}$ along each trajectory for each time-step using daily averaged $\mathrm{OH}$ concentrations and daily averaged actinic fluxes 
Table 1. Yearly Averaged Global Lifetimes (Days) of Different VSLS Emitted in Different Seasons From Europe, Mid-latitude North America, East Asia and the Indian Subcontinent ${ }^{\mathrm{a}}$

\begin{tabular}{|c|c|c|c|c|}
\hline $\begin{array}{l}\text { Lifetime } \\
\text { (days) }\end{array}$ & Europe & $\begin{array}{l}\text { Mid-latitude } \\
\text { North } \\
\text { America }\end{array}$ & $\begin{array}{l}\text { East } \\
\text { Asia }\end{array}$ & $\begin{array}{c}\text { Indian } \\
\text { Subcontinent }\end{array}$ \\
\hline $\mathrm{CH}_{3} \mathrm{CH}_{2} \mathrm{Br}$ & 66 & 60 & 51 & 40 \\
\hline $\mathrm{CH}_{2}=\mathrm{CBrCF}_{3}$ & 7.1 & 4.4 & 3.6 & 3.1 \\
\hline $\mathrm{n}-\mathrm{C}_{3} \mathrm{H}_{7} \mathrm{Br}$ & 27 & 20 & 15 & 11 \\
\hline $\mathrm{C}_{2} \mathrm{HCl}_{3}$ & 12 & 7.6 & 5.7 & 4.5 \\
\hline $\mathrm{CCl}_{3} \mathrm{CHO}$ & 24 & 17 & 12 & 8.5 \\
\hline $\mathrm{CH}_{3} \mathrm{I}$ & 11 & 8.7 & 7.9 & 6.7 \\
\hline $\mathrm{CF}_{3} \mathrm{I}$ & 5.1 & 3.8 & 3.6 & 3.2 \\
\hline $\mathrm{C}_{3} \mathrm{~F}_{7} \mathrm{I}$ & 2.85 & 2.26 & 2.2 & 1.8 \\
\hline $\mathrm{CH}_{2} \mathrm{ClI}$ & 2.3 & 1.9 & 1.8 & 1.6 \\
\hline $\mathrm{CHBr}_{3}$ & 47 & 43 & 39 & 33 \\
\hline
\end{tabular}

${ }^{\mathrm{a}}$ The VSLS of $\mathrm{CH}_{3} \mathrm{I}, \mathrm{CF}_{3} \mathrm{I}, \mathrm{C}_{3} \mathrm{~F}_{7} \mathrm{I}, \mathrm{CH}_{2} \mathrm{ClI}$, and $\mathrm{CHBr}_{3}$ are removed mostly via photolysis while the others are removed by mostly via reaction with $\mathrm{OH}$.

from the MOZART-4 model output [Emmons et al., 2009] appropriate for that time and location. The photolysis rates were calculated using the Tropospheric Ultraviolet and Visible (TUV) Radiation Model (http://cprm.acd.ucar.edu/ Models/TUV/) and the actinic flux from MOZART-4. OH loss rates and absorption cross sections are taken from JPL 2006 and 2009 (http://jpldataeval.jpl.nasa.gov). We impose a diurnal cycle based on the daily averaged $\mathrm{OH}$ concentrations and actinic flux. The variability and uncertainties of these terms result in an uncertainty in $\beta$ of about $20 \%$. The calculated tropospheric lifetime (Table 1) are in good agreement with those from previous studies, e.g., Wuebbles et al. [2001] for n-propyl bromide and Li et al. [2006] for $\mathrm{CF}_{3}$ I. Any halogen derived from chemicals undergoing degradation can be removed by wet deposition. This loss was estimated by applying a wet scavenging mechanism along the trajectories in the model based on cloud and precipitation information from the ECMWF ERA-interim output. We assumed that the products of VSLS degradation are highly soluble with a Henry's law coefficient of $10^{5} \mathrm{M} / \mathrm{atm}$; this provides a good upper limit of the degradation rate.

\section{Results and Discussion}

[11] We have calculated $\beta$, ODPs, and lifetimes of five VSLS halocarbons that are predominantly lost via reaction with $\mathrm{OH}\left(\mathrm{CH}_{3} \mathrm{CH}_{2} \mathrm{Br}, \mathrm{CH}_{2}=\mathrm{CBrCF}_{3}, \mathrm{n}-\mathrm{C}_{3} \mathrm{H}_{7} \mathrm{Br}, \mathrm{C}_{2} \mathrm{HCl}_{3}\right.$, $\mathrm{CCl}_{3} \mathrm{CHO}$ ) and five that are predominantly photolyzed $\left(\mathrm{CH}_{3} \mathrm{I}, \mathrm{CF}_{3} \mathrm{I}, \mathrm{C}_{3} \mathrm{~F}_{7} \mathrm{I}, \mathrm{CH}_{2} \mathrm{ClI}, \mathrm{CHBr}_{3}\right)$. The first three species in each group are considered to be potential replacements for longer-lived halogenated compounds currently used in industrial activities. Of the rest, $\mathrm{CCl}_{3} \mathrm{CHO}$ is a product of methyl chloroform degradation in the troposphere; $\mathrm{CH}_{2} \mathrm{ClI}$ and $\mathrm{CHBr}_{3}$ are known natural emissions from the oceans. We chose these compounds to cover a range of tropospheric lifetimes.

[12] The yearly averaged lifetimes of the different VSLS species (Table 1) vary strongly with emission region owing to gradients in $\mathrm{OH}$ concentration and actinic flux. VSLSs emitted from the Indian subcontinent, the most tropical region considered, exhibit the shortest lifetimes because of larger $\mathrm{OH}$ concentrations and larger actinic flux, while emissions from Europe have the longest lifetimes due to lower $\mathrm{OH}$ concentrations and lower actinic flux. Note that the temperature dependence of the $\mathrm{OH}$ reaction is very small for all VSLS studied here, and the photolysis rate is assumed to be temperature independent; thus, temperature has a minimal effect on the lifetime.

[13] Figure 1 shows the variation of $\beta(\mathrm{s}, \mathrm{t})$ with the VSLS lifetime as a function of season and region of emission (seasonally averaged over 3 years). Only a few percent of the emitted VSLSs considered here are irreversibly transported to the stratosphere from any of these regions; this is to be expected and has been the main reason for using substitutes with very short lifetimes. However, there are significant differences in the fraction that does reach the stratosphere. In all seasons and for each emission region, $\beta(\mathrm{s}, \mathrm{t})$ increases with increasing lifetime. For each season, the largest $\beta(\mathrm{s}, \mathrm{t})$ for a given tropospheric lifetime is found for VSLSs emitted from the Indian subcontinent, and the lowest from Europe. This dependence on emission region is the most significant factor for these ODPs, with variations of factors of 50 to 100 for shorter-lived species ( days) and a factor of 10 for longer-lived species ( $\sim 30$ days). Emissions with the largest $\beta$ are those from low latitudes in summer. In summer, emissions from mid-latitude North America enter the TTL through the North American monsoon, while emissions from the Indian subcontinent and East Asia enter the TTL through the Asian monsoon (see auxiliary material).
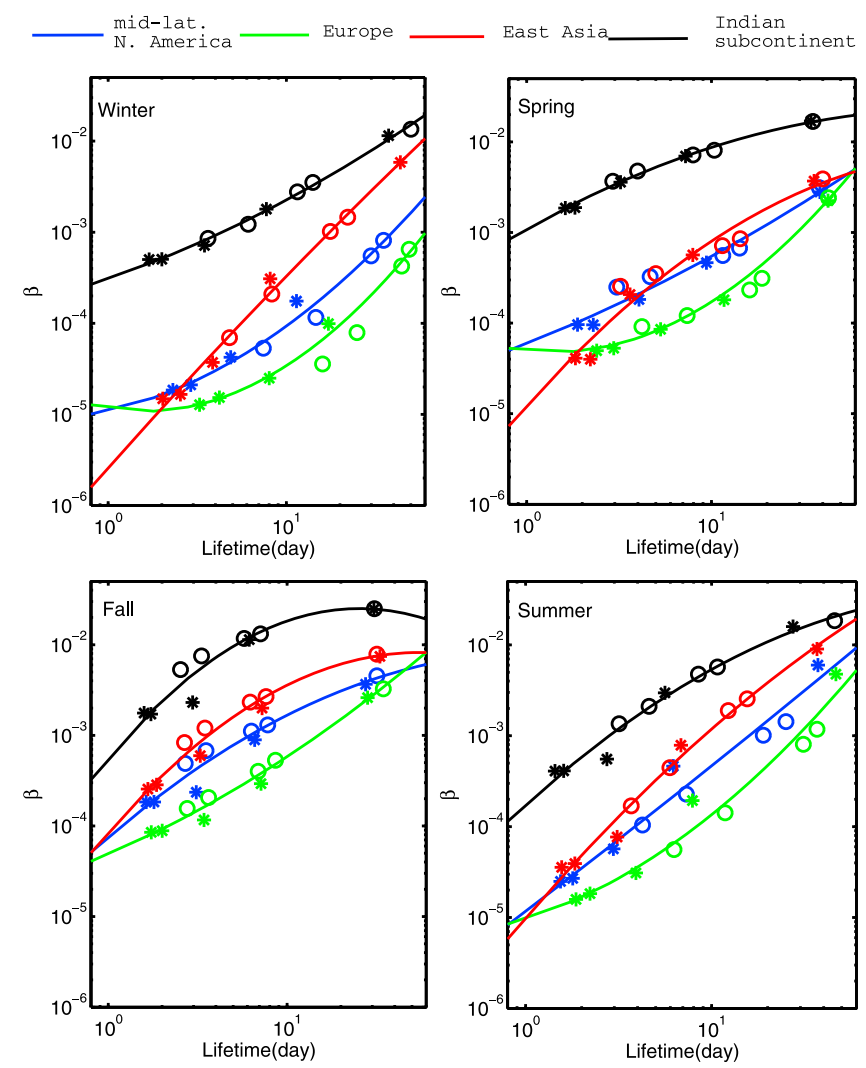

Figure 1. Variation of mass fraction of VSLS and its products reaching the stratosphere $(\beta)$ plotted against the seasonally varying tropospheric lifetime of the VSLS. Values of $\beta$ are calculated for different seasons and regions of emission (color code). Also shown are the results for VSLS with predominantly photolytic loss (stars) and $\mathrm{OH}$ loss (circles). The lines through the stars and circles are fits to equation (2) using the parameters of Table 2. 
Table 2. Regression Coefficients of the Relationship Between the Seasonal Lifetime and $\beta$, the Fraction of Mass Reaching the Stratosphere ${ }^{\mathrm{a}}$

\begin{tabular}{|c|c|c|c|}
\hline Season & $\mathrm{a}$ & $\mathrm{b}$ & d \\
\hline \multicolumn{4}{|c|}{ Europe } \\
\hline Winter & 0.342 & -0.3195 & $1.16 \mathrm{E}-05$ \\
\hline Spring & 0.33 & -0.2191 & $4.93 \mathrm{E}-05$ \\
\hline Summer & 0.1 & 0.8478 & $4.89 \mathrm{E}-05$ \\
\hline Fall & 0.218 & 0.6445 & $9.65 \mathrm{E}-06$ \\
\hline \multicolumn{4}{|c|}{ Mid-latitude North America } \\
\hline Winter & 0.2172 & 0.4297 & $1.10 \mathrm{E}-05$ \\
\hline Spring & 0.0672 & 0.8079 & $5.95 \mathrm{E}-09$ \\
\hline Summer & -0.1521 & 1.6934 & $7.57 \mathrm{E}-05$ \\
\hline Fall & 0.017 & 1.5609 & $1.17 \mathrm{E}-05$ \\
\hline \multicolumn{4}{|c|}{ East Asia } \\
\hline Winter & -0.0395 & 2.19 & $2.59 \mathrm{E}-06$ \\
\hline Spring & -0.202 & 2.28 & $1.23 \mathrm{E}-05$ \\
\hline Summer & -0.2832 & 2.28 & $8.52 \mathrm{E}-05$ \\
\hline Fall & -0.1274 & 2.37 & $9.91 \mathrm{E}-06$ \\
\hline \multicolumn{4}{|c|}{ Indian Subcontinent } \\
\hline Winter & 0.081 & 0.68 & $3.10 \mathrm{E}-04$ \\
\hline Spring & -0.109 & 1.15 & 0.0011 \\
\hline Summer & -0.364 & 2.35 & $5.57 \mathrm{E}-04$ \\
\hline Fall & -0.159 & 1.86 & $1.70 \mathrm{E}-04$ \\
\hline
\end{tabular}

${ }^{a}$ See Figure 1 and the text for details.

The loss mechanism (photolysis or $\mathrm{OH}$ reaction) does not appreciably affect $\beta(\mathrm{s}, \mathrm{t})$, as illustrated by photolytic (stars) and $\mathrm{OH}$ loss (circles) lifetimes falling on the same curve in Figure 1.

[14] Based on our analysis, one can calculate $\beta(s, t)$ knowing its tropospheric lifetime for a particular season and emission region using the following formula:

$$
\beta_{x}(s, t)=c(s, t) \tau^{b(s, t)+[a(s, t) \ln \tau(s, t)]}, \text { for } 1 \text { day }<\tau<40 \text { days }
$$

where $\tau(\mathrm{s}, \mathrm{t})$ is the global lifetime (in days) for emission in a given season and location, and $\beta(\mathrm{s}, \mathrm{t})$ is the fraction of emitted mass reaching the stratosphere. The factors $\mathrm{a}, \mathrm{b}$ and $\mathrm{c}$ are coefficients derived by fitting the data shown in Figure 1 (on a log-log scale) to a second order polynomial using a least squares method; the obtained coefficients are given in Table 2 and the fits are shown in Figure 1.

[15] Figure 2 presents the time series of $\operatorname{ODP}(\mathrm{s}, \mathrm{t}), \beta(\mathrm{s}, \mathrm{t})$, and lifetime from September 2003 to July 2006 for $\mathrm{CH}_{3} \mathrm{I}$. Figure 2 shows the main features found in our calculations for the VSLS with a lifetime shorter than 10 days. It is evident from Figure 2 and Tables S1-S4 in the auxiliary material that the ODPs vary significantly with the season of emission. There is a significant annual cycle in $\operatorname{ODP}(\mathrm{s}, \mathrm{t})$ and $\beta(\mathrm{s}, \mathrm{t})$ resulting from seasonal variations of tropospheric lifetime, vertical transport into the TTL, and transport through the depth of the TTL. For VSLS with a lifetime shorter than 10 days, $\operatorname{ODP}(\mathrm{s}, \mathrm{t})$ and $\beta(\mathrm{s}, \mathrm{t})$ have maxima in June/July and minima in January/February. For VSLS with a lifetime longer than 30 days (e.g., Figure S1 in the auxiliary material), $\operatorname{ODP}(\mathrm{s}, \mathrm{t})$ and $\beta(\mathrm{s}, \mathrm{t})$ have maxima in November/December and minima in April/May, except for the Indian subcontinent which still has maxima in June/July. In contrast, Gettelman et al. [2009] found a maximum in transport during December/February in the tropics $\left(20^{\circ} \mathrm{S}\right.$ to $\left.20^{\circ} \mathrm{N}\right)$. These findings demonstrate the interplay between transport efficiency and lifetimes and that there is a different seasonality in the tropics than in the northern subtropics or midlatitudes. Figure 2 shows the interplay between lifetime and transport from different emission regions for $\mathrm{CH}_{3} \mathrm{I}$. The seasonal cycle of tropospheric lifetime runs counter to that of the vertical transport into the stratosphere, with the net effect of partially offsetting the seasonal cycle of the calculated $\operatorname{ODP}(\mathrm{s}, \mathrm{t})$. It is also interesting to note that during summertime, the lifetimes of the different compounds have little regional variability, because the latitudinal gradient of actinic flux is less pronounced in summer than in winter. However, $\beta$ and ODPs have the highest regional variability (Figure 2) at this time because of large differences in transport rates. On average, ODPs of VSLS emitted from the Indian subcontinent are 22, 11, and 8 times larger, respectively, than those from Europe, mid-latitude North America, and East Asia. Transport efficiency variations with region are more important than atmospheric loss variations for these short-lived compounds; the regions with the largest ODPs are the ones with the shortest lifetimes. Using our seasonally dependent ODPs, we can calculate the yearly averaged ODPs. Such values for mid-latitude emissions (North America and Europe) agree with those found by
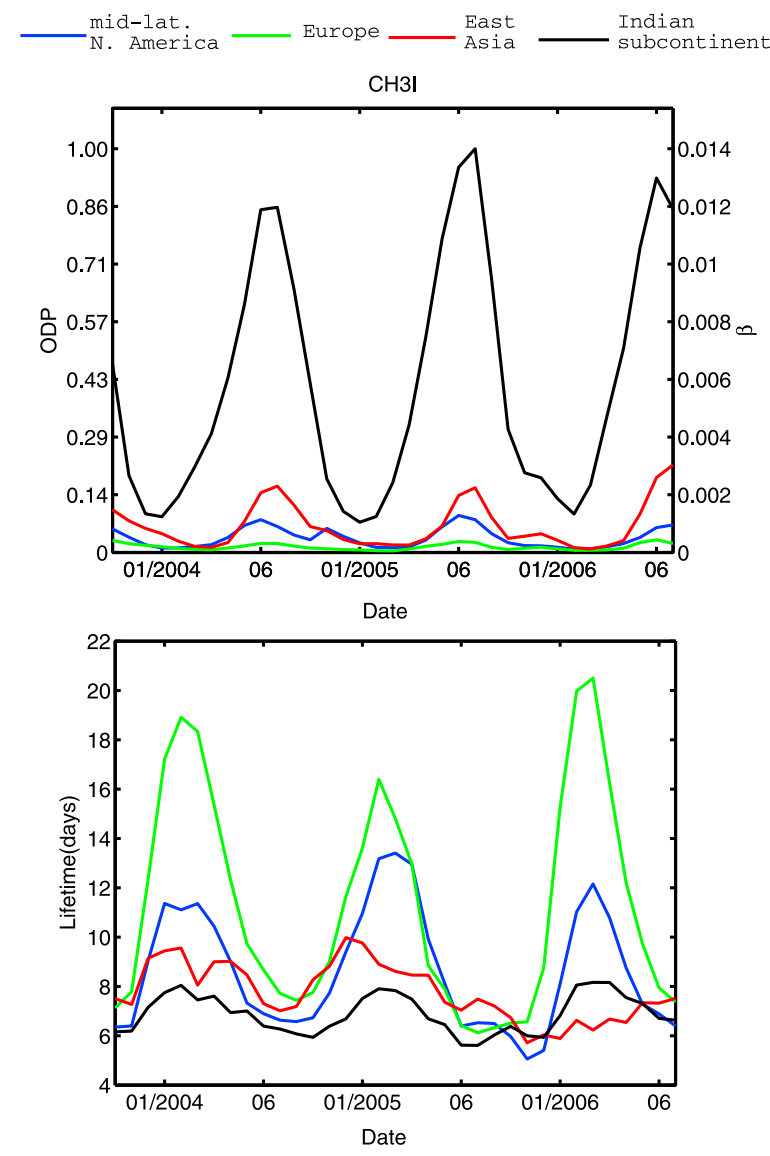

Figure 2. Time series of (top) ODP and $\beta$, and (bottom) global lifetime of $\mathrm{CH}_{3} \mathrm{I}$ for emissions from mid-latitude North America (blue), Europe (green), East Asia (red) and Indian subcontinent (black), from September 2003 to July 2006. ODPs are calculated assuming $\frac{\zeta_{x} \tau_{\text {strat }}^{x}}{\zeta_{C F C-11} \tau_{\text {strat }}^{C F C-11}}$
equals 1. 
Wuebbles et al. [2001, 2009], within a factor of 2 for $\mathrm{n}-\mathrm{C}_{3} \mathrm{H}_{7} \mathrm{Br}, 1.5$ for $\mathrm{CH}_{3} \mathrm{I}$ and 0.7 for $\mathrm{CF}_{3} \mathrm{I}$.

[16] As noted above, the seasonal variation of vertical transport into the TTL is the dominant factor in determining the variations in $\operatorname{ODP}(\mathrm{s}, \mathrm{t})$. It is important to note that the highest seasonal ODP value can be much higher than the yearly average. Therefore the question of how the emissions vary with season is an important issue. For example, while the yearly averaged ODP of $\mathrm{CH}_{3} \mathrm{I}$ is 0.6 for emissions from the Indian subcontinent, its peak value (of 1 during summertime) is the same as that of CFC- 11 .

\section{Conclusions}

[17] We have used the FLEXPART Lagrangian particle dispersion model to assess the VSLS transport efficiency to the stratosphere, its dependence on the season and location of emission, and its interannual variability. We examine how transport efficiency and emission location influence the ODP and demonstrate that the ODPs of the VSLS considered here are determined more by the efficiency of transport from the boundary layer in the emission region into the stratosphere than by the regional variations in tropospheric lifetimes. The consistent dependence of the fraction of VSLS reaching the stratosphere on the location and season of emission allows us to propose a simple formula that enables the estimation of ODPs of other short-lived anthropogenic gases without reliance on a 3-D model. The large seasonal variations in ODPs of VSLS suggest that yearly averaged ODP values for these compounds may be less appropriate than for long-lived species. Instead, using a range of ODPs that accounts for emission region and season may be more informative.

[18] Acknowledgments. We thank Vladimir Orkin for providing some of the loss rates used in the paper and Chi-Fan Shih for providing ERA-interim data. AS was supported by the European Commission as part of the SHIVA project. This work was supported by NOAA Climate Research Program.

\section{References}

Aschmann, J., B.-M. Sinnhuber, E. L. Atlas, and S. M. Schauffler (2009), Modeling the transport of very short-lived substances into the tropical upper troposphere and lower stratosphere, Atmos. Chem. Phys., 9, 9237-9247, doi:10.5194/acp-9-9237-2009.
Berthet, G., J. G. Esler, and P. H. Haynes (2007), A Lagrangian perspective of the tropopause and the ventilation of the lowermost stratosphere, J. Geophys. Res., 112, D18102, doi:10.1029/2006JD008295.

Emanuel, K. A., and M. Živković-Rothman (1999), Development and evaluation of a convection scheme for use in climate models, J. Atmos. Sci., 56, 1766-1782, doi:10.1175/1520-0469(1999)056<1766:DAEOAC> 2.0.CO;2.

Emmons, L. K., et al. (2009), Description and evaluation of the Model for Ozone and Related chemical Tracers, version 4 (MOZART-4), Geosci. Model Dev. Discuss., 2, 1157-1213, doi:10.5194/gmdd-2-1157-2009.

Fueglistaler, S., A. E. Dessler, T. J. Dunkerton, I. Folkins, Q. Fu, and P. W. Mote (2009), Tropical tropopause layer, Rev. Geophys., 47, RG1004, doi:10.1029/2008RG000267.

Gettelman, A., P. H. Lauritzen, M. Park, and J. E. Kay (2009), Processes regulating short-lived species in the tropical tropopause layer, J. Geophys. Res., 114, D13303, doi:10.1029/2009JD011785.

James, P., A. Stohl, C. Forster, S. Eckhardt, P. Seibert, and A. Frank (2003), A 15-year climatology of stratosphere-troposphere exchange with a Lagrangian particle dispersion model: 2. Mean climate and seasonal variability, J. Geophys. Res., 108(D12), 8522, doi:10.1029/ 2002JD002639.

Ko, M. K. W., et al. (2003), Very short-lived halogen and sulfur substances, in Scientific Assessment of Ozone Depletion: 2002, Global Ozone Res. Monit. Proj. Rep., 47, chap. 2, World Meteorol. Organ., Geneva, Switzerland.

Law, K. S., et al. (2007), Halogenated very short-lived substances, in Scientific Assessment of Ozone Depletion: 2006, Global Ozone Res. Monit. Proj. Rep., 50, chap. 2, World Meteorol. Organ., Geneva, Switzerland.

Li, Y., K. O. Patten, D. Youn, and D. J. Wuebbles (2006), Potential impacts of $\mathrm{CF}_{3} \mathrm{I}$ on ozone as a replacement for $\mathrm{CF}_{3} \mathrm{Br}$ in aircraft applications, Atmos. Chem. Phys., 6, 4559-4568, doi:10.5194/acp-6-4559-2006.

Rosenlof, K. H. (1995), Seasonal cycle of the residual mean meridional circulation in the stratosphere, J. Geophys. Res., 100(D3), 5173-5191, doi:10.1029/94JD03122.

Stohl, A., C. Forster, A. Frank, P. Seibert, and G. Wotawa (2005), Technical note: The Lagrangian particle dispersion model FLEXPART version 6.2, Atmos. Chem. Phys., 5, 2461-2474, doi:10.5194/acp-5-2461-2005.

Wuebbles, D. J., K. O. Patten, M. T. Johnson, and R. Kotamarthi (2001), New methodology for Ozone Depletion Potentials of short-lived compounds: n-Propyl bromide as an example, J. Geophys. Res., 106, 14,551-14,571, doi:10.1029/2001JD900008.

Wuebbles, D. J., D. Youn, K. Patten, D. Wang, and M. Martínez-Avilés (2009), Metrics for ozone and climate: Three-dimensional modeling studies of ozone depletion potentials and indirect global warming potentials, in Twenty Years of Ozone Decline, edited by C. Zerefos, G. Contopoulos, and G. Skalkeas, pp. 297-326, Springer, Dordrecht, Netherlands.

J. Brioude, O. R. Cooper, J. S. Daniel, G. J. Frost, C. Granier, R. W. Portmann, A. R. Ravishankara, and K. H. Rosenlof, Chemical Sciences Division, Earth System Research Laboratory, NOAA, 325 Broadway, Boulder, CO 80305, USA. (jerome.brioude@noaa.gov)

S. A. Montzka, Global Monitoring Division, Earth System Research Laboratory, NOAA, 325 Broadway, Boulder, CO 80305, USA.

A. Stohl, Norwegian Institute for Air Research, PO Box 100, N-2027 Kjeller, Norway. 